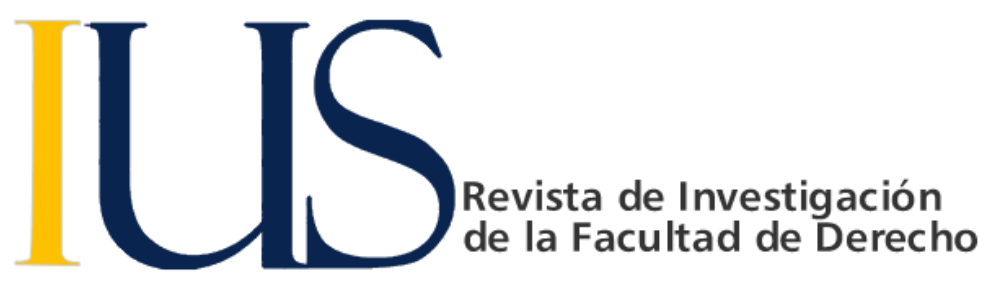

\title{
El Tribunal Constitucional como instaurador de la jurisdicción constitucional
}

Katherine Alvarado Tapia ${ }^{1}$

\begin{tabular}{ll}
\hline INFORMACIÓN DEL ARTÍCULO & RESUMEN \\
\hline Historia del artículo: & El presente artículo analiza críticamente el origen kelseniano y la naturaleza \\
Recibido el 23 de mayo de 2011 & jurídica del Tribunal Constitucional como expresión de la jurisdicción \\
Aceptado el 15 de junio de 2011 & constitucional, examinando las diversas teorías que la estudian, no sin antes \\
& detallar la necesaria diferenciación entre defensa de la Constitución, control \\
Palabras clave: & de la constitucionalidad, justicia constitucional y jurisdicción constitucional. \\
Tribunal Constitucional & Así, se explican las teorías que entienden al Tribunal Constitucional como \\
Jurisdicción constitucional & órgano único, como órgano legislativo (negativo), como órgano \\
Justicia constitucional & jurisdiccional, como órgano político y como órgano de control de la \\
Control de constitucionalidad & constitucionalidad
\end{tabular}

The Constitutional Court as constituent of the constitutional jurisdiction

\section{Introducción}

La presencia de la jurisdicción constitucional, es consecuencia lógica del Estado constitucional de derecho pues a este pertenecen entre otros el principio de supremacía constitucional. Este principio fundamental, determina -desde una perspectiva objetiva- que la Constitución presida el ordenamiento jurídico, de allí que se pueda señalar que es lex superior y por tanto obliga por igual a gobernantes como a gobernados y -desde una perspectiva subjetiva- que la Constitución no puede ser vulnerada válidamente por ningún acto de los poderes estatales o la colectividad en general.

La jurisdicción constitucional, enmarca un sistema jurídico-político que establece y permite el control del poder, de manera que los diversos poderes estatales pueden limitarse mutuamente así como mediante su división y distribución. En otras palabras permite que el poder pueda frenar al poder. Sólo en un sistema donde exista el control del poder puede haber garantía esencial de todos los valores de la propia democracia como el respeto a la voluntad popular, la vigencia de los derechos humanos, el pluralismo político y la alternancia en el ejercicio del poder.

La jurisdicción especializada, nace en forma de un Tribunal Constitucional que, siguiendo los parámetros kelsenianos, queda fuera del Poder Judicial y de la clásica división tripartita de los poderes, actuando como un "legislador negativo", y monopolizando la función de rechazo de las leyes contrarias a la Constitución, que serán expulsadas del ordenamiento con efectos "erga omnes" cuando el Tribunal Constitucional declare su contradicción con la norma fundamental.

De acuerdo esta preliminar definición el Tribunal Constitucional, representa dos cosas: un intento de conciliar la garantía de la Constitución y la libertad política del Poder Legislativo frente a los jueces y al mismo tiempo un intento por recuperar el ideal de la aplicación racional y controlable del derecho.

En el presente trabajo analizaremos críticamente el origen kelseniano y la naturaleza jurídica del Tribunal

\footnotetext{
${ }^{1}$ Abogada, Magíster en Derecho Constitucional. Profesora de Derecho Constitucional de la Universidad Católica Santo Toribio de Mogrovejo, Chiclayo, Perú. Contacto: kalvarado@usat.edu.pe
} 
Constitucional como expresión de la jurisdicción constitucional, examinando las diversas teorías que justifican su presencia en el Estado de Derecho, la cual pues no siempre ha sido pacífica por el contrario es generadora de una polémica inacabable por su naturaleza jurídica, por las funciones que desempeña como órgano especializado, por su ubicación en el sistema constitucional y finalmente por los alcances de las decisiones que adopta.

\section{UNA PRIMERA Y NECESARIA DIFERENCIACIÓN: DEFENSA, JUSTICIA $Y$ JURISDICCIÓN CONSTITUCIONAL}

Iniciaremos este breve análisis metódico sobre la relación que guarda el Tribunal Constitucional -en adelante TC-, con la Jurisdicción Constitucional, estableciendo una previa aclaración de algunos conceptos vinculados a la garantía de la indemnidad constitucional.

Así tenemos que, en un primer momento, es el jurista alemán, Carl Schmitt, quien utiliza por primera vez el término "Defensa de la Constitución", mientras que entre los constitucionalistas franceses ha predominado el concepto de "Control de la constitucionalidad", en tanto que un sector de los juristas italianos se refiere a la "Justicia constitucional" y en un sentido parecido, los tratadistas alemanes hablan de "Jurisdicción Constitucional"2.

La "Defensa de la Constitución", se concibe como aquel sistema que permite la protección y permanencia de las disposiciones constitucionales contra las extralimitaciones de los órganos del poder, que tienden a desbordarse con mayor razón en nuestros tiempos en que intervienen de manera predominante en las relaciones sociales. En tal sentido resulta beneficioso el análisis de los medios e instrumentos establecidos por los mismos Constituyentes para que las normas consagradas en la propia Constitución adquieran eficacia, para que las disposiciones más importantes de la vida jurídica de cumplan efectivamente en la práctica

\footnotetext{
${ }^{2}$ Cfr. FIX ZAMUDIO, Héctor, Veinticinco años de evolución de la Justicia Constitucional (1940-1965), UNAM, México, 1968, p.12.

${ }^{3}$ FIX ZAMUDIO, Héctor, Introducción al estudio de la Defensa de la Constitución, En: Boletín Mexicano de

Derecho de Derecho Comparado. № 01, 1968, pp. 90-91.

${ }^{4}$ FIX ZAMUDIO, Héctor y otro, Derecho Constitucional Comparado y Mexicano, Porrùa, México, 2001, p.
}

y sobre todo para que se respeten ineludiblemente los derechos que la misma Carta Fundamental establece en beneficio de los habitantes del país.

Esta idea no es nueva sino por el contrario la encontramos desde tiempos bastante remotos incluso entre los griegos y romanos pero si bien es cierto, los instrumentos de tutela constitucional ya eran conocidos, el estudios sistemático de los mismos, su análisis dogmático y científico, es por el contrario muy reciente ${ }^{3}$ surge con posterioridad a la Primera Guerra Mundial, es en los años treinta del siglo pasado, y si se quiere fijar una fecha para considerarla como el inicio de la sistematización de esta importante disciplina, se puede partir del clásico libro de Carl Schmitt -“Der Hüter der Verfassung"- literalmente, "El protector de la Constitución", cuya primera edición apareció en Alemania en 1931 y fue traducido al español en el mismo año bajo el título de "La Defensa de la Constitución", dicha investigación origina la famosa polémica con el jurista fundador de la Escuela de Viena, Hans Kelsen, quien sobre el tema, publica una réplica denominada ¿Wer soll der Hüter der Verfassung sein?, “¿Quién debe ser el protector de la Constitución?" 4 aparecida también en el año 1931.

Carl Schmitt ${ }^{5}$ incluye dentro de este concepto genérico de Defensa Constitucional, a todos los medios que se ha ido creando a lo largo de la interminable lucha del hombre para limitar el poder y sujetarlo a los límites que le fija la Constitución.

Fix Zamudio ${ }^{6}$ establece una división en cuanto al concepto genérico de defensa constitucional y de esta manera se pueden hallar dos categorías esenciales que califica -para poder distinguirlas- en medios protectores de la Carta Fundamental por un lado y por el otro, las garantías constitucionales. Para entender gráficamente la distinción utiliza un símil de carácter biológico, partiendo de la base de que la "Protección de la Constitución" estima como el primer sector de la Defensa misma de la Constitución, está formada por todos los medios, instrumentos e instituciones que el

174.

5 SCHMITT, Carl, La Defensa de la Constitución, Traducido por Pedro De Vega, Tecnos, Madrid 1983, pp.

9-20.

${ }^{6}$ Cfr. FIX ZAMUDIO, Héctor, Introducción al estudio de la Defensa de la Constitución, Ob. Cit. p. 92 
Poder Constituyente ha estimado necesarios para mantener los poderes políticos dentro de las esferas que se han trazado en la Ley Suprema, y por tanto, a través de los mismos, se tiende a lograr la marcha armónica y equilibrada de los mismos factores entre sí, o en otras palabras, a la coordinación armónica de los diversos organismos en que se divide el supremo poder político para su ejercicio y de esta manera lograr, por el mismo equilibrio de las instituciones, que se respeten los límites que a dicho ejercicio de la autoridad ha establecido la Carta Fundamental, y en consecuencia, también ser respeten los derechos esenciales de la persona consagrados en la Constitución.

En tal virtud, es posible caracterizar figurativamente este sector de la Defensa Constitucional, estableciendo que los instrumentos que lo integran están dirigidos al aspecto fisiológico de la Ley Suprema, ya que tienen por objeto lograr el adecuado funcionamiento de los órganos del poder.

En un sentido diverso se debe entender a las "garantías constitucionales", consideradas, en su sentido técnico jurídicos como aquellos medios, instrumentos, sistemas de carácter procesal, que funcionan subsidiariamente respecto de los que forman parte de la "Protección", ya que han establecido precisamente en el supuesto de que los citados instrumentos protectores han sido insuficientes para evitar las extralimitaciones de los órganos de poder.

En efecto, cuando los sistemas de protección han sido rebasados por los titulares de los organismos de autoridad, resulta indispensable el establecimiento de otras instituciones que contengan dichas extralimitaciones, las repriman, y si es posible, reintegren el orden jurídico constitucional violado y éstas son precisamente las garantías constitucionales, que utilizando el mismo símil, se refieren al aspecto patológico de la Constitución, y en el mismo sentido podemos calificar a estos medios de garantía, como instrumentos terapéuticos para corregir los desórdenes, sumamente graves, producidos por la violación de las normas y los principios fundamentales contenidos en la Ley Suprema.

\footnotetext{
7 Cfr. DIAZ REVORIO, Francisco Javier, Tribunal Constitucional y procesos constitucionales en España: algunas reflexiones tras la
}

Ahora bien, corresponde desarrollar dos términos que muchos doctrinarios utilizan como sinónimos, Justicia constitucional y Jurisdicción Constitucional.

Se entiende por "Justicia constitucional"7 al conjunto de procedimientos, vías o mecanismos de garantía jurisdiccional de la Constitución. Se trata, por tanto, de uno entre los diversos instrumentos de defensa constitucional; sin embargo, desde la perspectiva jurídica tiende a entenderse que la garantía jurisdiccional de la Constitución es imprescindible para que la misma pueda considerarse norma jurídica suprema. En este sentido puede llegar a decirse que no hay Constitución (al menos en sentido jurídicoformal) sin Justicia constitucional, y de hecho los Estados que se han dotado de una norma jurídica suprema escrita han implantado en algún momento alguna forma de garantía jurisdiccional de esa superioridad normativa. De este modo, la Justicia constitucional existe con independencia de que haya o no un órgano jurisdiccional específicamente encargado de la garantía constitucional, e incluso de que existan o no procesos constitucionales en el sentido estricto al que luego nos referiremos.

El origen de la Justicia constitucional, entendida con el significado al que nos venimos refiriendo, se produce en 1803 en los Estados Unidos, con el célebre caso Marbury contra Madison, en la que el juez John Marshall dedujo de la norma suprema que cualquier juez, enfrentado a una norma contraria a la Constitución, debe aplicar ésta e inaplicar aquélla. No hay, por tanto, en este modelo de justicia constitucional que se ha dado en llamar "difuso", ni Tribunal Constitucional ni procesos específicamente constitucionales, dado que se encomienda el control de constitucionalidad a los tribunales ordinarios en los distintos tipos de procesos.

En cambio, la idea de Jurisdicción Constitucional hace referencia al órgano $u$ orden jurisdiccional específicamente encargado de garantizar la supremacía constitucional. Así entendida la Jurisdicción Constitucional, puede o no existir, dado que, como se ha mencionado, puede haber garantía jurisdiccional de la Constitución sin que exista un órgano jurisdiccional especializado en esa labor. A diferencia de la Justicia

reforma de la Ley Orgánica del Tribunal Constitucional de 2007, Estudios Constitucionales, Año 7, № 02, 2009, pp. 82-83. 
constitucional, que surgió prácticamente en los orígenes del constitucionalismo para dar respuesta a la necesidad de garantizar el carácter de norma suprema de la Constitución, la jurisdicción especializada en lo constitucional, no surgió hasta el primer tercio del siglo XX, y no se extendió a la totalidad de los países con Constitución jurídica escrita.

Se puede afirmar entonces que, la jurisdicción especializada, nace en forma de un Tribunal Constitucional que, siguiendo los parámetros kelsenianos, queda fuera del Poder Judicial y de la clásica división tripartita de los poderes, actuando como un "legislador negativo", y monopolizando la función de rechazo de las leyes contrarias a la Constitución, que serán expulsadas del ordenamiento con efectos "erga omnes" cuando el Tribunal Constitucional declare su contradicción con la norma fundamental.

No obstante a lo antes indicado, actualmente puede decirse que ésta no es la única forma de Jurisdicción Constitucional, pues en algunos sistemas constitucionales se han introducido órganos $u$ órdenes jurisdiccionales específicamente constitucionales, dentro del Poder Judicial, como sucede con los sistemas de Sala Constitucional dentro de la Corte Suprema.

Resumiendo la relación desarrollada para cada una de las instituciones podemos deducir dos importantes consecuencias:

Que, el término "Justicia constitucional" indica en sentido lato al conjunto de procedimientos de carácter procesal por medio de los cuales se encarga, a determinados órganos del Estado, la imposición forzosa de los mandamientos jurídicos supremos, a aquellos otros organismos de carácter público que han desbordado las limitaciones, que para su actividad se establecen la misma Constitución; y "Jurisdicción Constitucional" alude en sentido restringido, al estudio de la actividad de verdaderos tribunales, formal y materialmente considerados, que conozcan y resuelvan las controversias de naturaleza constitucional de manera específica, es decir que los citados tribunales están especializados en la decisión de los conflictos de carácter constitucional, y aunque la tendencia es creciente hacia la configuración de estos órganos jurisdiccionales especializados, existen numerosos regímenes en los cuales las normas de carácter judicial constitucional se atribuyen a órganos de carácter político, o bien a los jueces ordinarios ${ }^{8}$.

Blancas Bustamante ${ }^{9}$ sostiene que son elementos principales de la Jurisdicción Constitucional: la jurisdicción, las garantías constitucionales, el proceso y los órganos constitucionales. A continuación abordaremos brevemente cada uno de ellos.

- Jurisdicción, entendida como la función pública realizada por órganos del Estado con las formas requeridas por la ley; para solucionar conflictos de intereses, controlar conductas antisociales (faltas o delitos), resolver incertidumbres jurídicas y también para controlar la constitucionalidad normativa a través de órganos especializados que aplican el derecho al caso concreto, promoviendo la paz social en justicia.

- Garantías constitucionales, que son instrumentos protectores que se encuentran establecidos el ordenamiento constitucional, como el habeas corpus, el amparo, el proceso de inconstitucionalidad.

- Proceso, como el desarrollo o secuencia de actos con el objeto de resolver frente al órgano jurisdiccional, un conflicto con la finalidad de hacer valer determinadas pretensiones;

- Órganos constitucionales, que son las entidades investidas de poder por el ordenamiento jurídico para realizar la labor tuitiva propia de este proceso. Algunos autores se inclinan por denominar a este apartado como "De la magistratura" ya que son los jueces (ordinarios o especiales) los que en la mayoría de las veces se encargan de las tareas básicas de la jurisdicción o control constitucionales. Sin embargo es preferible emplear el término órganos, pues con ello se incluye también a los órganos políticos (Congreso, Parlamento, etc.) que en muchos lugares tienen esta tarea, y también porque existen órganos (como el Consejo Constitucional

\footnotetext{
${ }^{8}$ Cfr. FIX ZAMUDIO, Héctor, Ob. Cit. p.15
} ${ }^{9}$ Cfr. BLANCAS BUSTAMENTE, Carlos y otro, Derecho Constitucional
General, Fondo Editorial PUCP, Tomo I, Lima, 1992, p. 461 
francés) que son más políticos que jurisdiccionales ${ }^{10}$.

Podemos afirmar, tal y como lo hace García Toma ${ }^{11}$ que la misión principal de la Jurisdicción Constitucional es defender y preservar la constitucionalidad, entendida esta como el vínculo de armonía y concordancia plena entre la Constitución y las demás normas que conforman el sistema jurídico que esta diseña. En este aspecto, la Jurisdicción Constitucional supone la imagen de un "guardián de la constitucionalidad". Dentro de la Jurisdicción Constitucional, es donde se ejerce la actividad del "control constitucional", viabiliza la utilización del conjunto de procesos que permiten asegurar la plena vigencia y respeto del orden constitucional, al que se encuentra sometida toda la normatividad que emane de los poderes constituidos y la conducta funcional de sus apoderados políticos

Consideramos después de este breve análisis que, el término más acertado para referirnos a aquella "capacidad de los órganos del Estado para pronunciarse sobre temas constitucionales y que sus decisiones sean de carácter vinculante" 12 es el de Jurisdicción Constitucional pues su contenido es la magistratura constitucional, o sea los órganos a quienes les corresponden fijar en definitiva: el contenido y alcance de los derechos fundamentales, el alcance de los principios políticos establecidos en la Constitución y la implicación que tienen las entidades, órdenes y órganos de gobierno que la propia Constitución establece.

\section{TRIBUNAL CONSTITUCIONAL}

\subsection{El TC como instaurador de la Jurisdicción Constitucional}

Los albores del TC se presencian en Europa después de la Primera Guerra Mundial, esta institución tuvo como protagonista a Hans Kelsen, quien participó

\footnotetext{
${ }^{10} \mathrm{Cfr}$. GARCÍA BELAUNDE, Domingo, Sobre la Jurisdicción constitucional, En: QUIROGA LEÓN, Aníbal. "Sobre la Jurisdicción Constitucional" Fondo Editorial de la PUCP, Lima, 1990. p. 36

11 GARCìA TOMA, Víctor, Teoría del Estado y Derecho Constitucional, Palestra, Lima, 2005, p.518

12 Cfr. GARCÍA BELAUNDE, Domingo, Sobre la Jurisdicción constitucional, Ob. Cit. p. 31.

${ }^{13}$ Cfr. ÖHLINGER, Theo, Hans Kelsen y el Derecho constitucional federal austriaco. Una retrospectiva crítica, En: Revista
}

activamente en la formación de la Constitución Federal de Austria de 1920.

Kelsen, según detalla el profesor Öhlinger ${ }^{13}$, inicialmente fue asesor de la Canciller del Estado Austriaco y como tal participó de una serie de proyectos constitucionales cuya sistemática influyó en todos los demás proyectos. Fue miembro de un Comité de alto rango compuesto de cuatro personas y que fue designado por el Gobierno del Estado entre mayo y junio de 1920 para la elaboración de un Proyecto constitucional (junto al canciller Renner, el Vicecanciller Jodok Fink y el Secretario de Estado Michael Mayr). Finalmente Kelsen fue convocado como experto a la Comisión constitucional de la Asamblea Nacional Constituyente que elaboró el texto de la Constitución federal desde el 11 de julio hasta el 24 de septiembre de 1920. Es así como -entre otros documentos- elabora el Proyecto de creación del Tribunal Constitucional austriaco (1918) el que posteriormente fue sancionado por la Asamblea Nacional Provisional de 1919, instituyendo dicho órgano en la Carta Austriaca de octubre de $1920 .{ }^{14}$

Pero Kelsen no fue el único creador del Tribunal Constitucional austriaco, pues hubo una serie de contribuciones de la comunidad jurídica austriaca en el período 1918-1920 que coadyuvó a crear esta institución y en las cuales Kelsen estuvo presente. Pero fue el que quizá influyó más, no solo por haber sido magistrado de dicho Tribunal y su relator permanente, sino por haber escrito sólidamente sobre este, en un momento en que nadie visualizaba el fundamento teórico del nuevo tipo de control ${ }^{15}$.

Es el propio Kelsen quien denomina a la Jurisdicción Constitucional como su "obra más personal" ${ }^{16}$ y es conocido que el Tribunal Constitucional austriaco es el TC especial más antiguo del mundo y ha influido considerablemente como tal en el desarrollo constitucional en Europa, sobre todo en la segunda

Iberoamericana de Derecho Procesal Constitucional. Número 5 (Enero-junio 2006), Primera Edición: 2006. p. 218

${ }^{14} \mathrm{Cfr}$. GARCÍA BELAUNDE, Domingo, De la Jurisdicción Constitucional al Derecho Procesal

Constitucional, Grijley, Lima, 2000, pp. 31.-32.

${ }^{15}$ GARCIA BELAUNDE, Domingo, Dos cuestiones disputadas sobre el Derecho Procesal Constitucional, En: Revista Iberoamericana de Derecho Procesal Constitucional. Número 7 (Enero-junio 2007), 2007.p. 3.

16 ÖHLINGER Theo. Ob. Cit. p. 219. 
mitad del siglo XX. Por ello, a este modelo austriaco de examen de constitucionalidad de las leyes se le designa también, sobre todo en los países romanistas, como modelo kelseniano.

Lo que evidentemente se debe a una sugerencia de Kelsen es la competencia del Tribunal Constitucional para examinar de oficio leyes que el Tribunal Constitucional tiene que aplicar en otro contexto (artículo 140 de la Constitución federa $\left.\right|^{17}{ }^{7}$ ). Los políticos habían previsto sólo una legitimación activa del Gobierno federal y de los Gobiernos de los Länder y habían concebido al Tribunal Constitucional, por así decirlo, como el árbitro en las controversias competenciales entre la Federación y los Länder. Fue precisamente esta competencia del Tribunal Constitucional la que se transformó en el motor del ulterior desarrollo de esta institución, e incluso lo transformó, de ser un mero árbitro entre la Federación y los Länder, en ser un amplio guardián de la Constitución $y$, en especial, de los derechos fundamentales.

Como ya es sabido, el sustento de Kelsen sobre el TC, tiene su punto de partida en que la Constitución es una norma jurídica, y no cualquiera, sino la primera de todas, lex superior, aquella que sienta los valores supremos de un ordenamiento y que desde esa supremacía es capaz de exigir cuentas, de erigirse en el parámetro de validez de todas las demás normas jurídicas del sistema ${ }^{18}$.

Kelsen, concibe el TC como un órgano especial de naturaleza legislativa, confiándole el control de la constitucionalidad salvaguardando la Constitución, es decir, garantizando que la Constitución no resultase falseada por leyes inferiores a ella, considerándola no sólo como el "vértice superior del ordenamiento jurídico, sino que es sobre todo, norma política que contiene los principios y postulados fundamentales

\footnotetext{
${ }^{17}$ Este precepto de la Constitución austriaca de octubre de 1920 decía, en su apartado 1. "El Tribunal Constitucional conoce de la inconstitucionalidad de las leyes de Land a instancia del Gobierno Federal, de la inconstitucionalidad de las leyes federales a instancia de un Gobierno de Land, así como de oficio en la medida en que una de estas leyes sea presupuesto de una sentencia del Tribunal Constitucional"

18 GARCÍA DE ENTERRÍA, Eduardo, La Constitución como norma y el Tribunal Constitucional, Editorial
}

para la organización política, social y económica de la Nación". ${ }^{19}$

Tal y como se ha señalado en el acápite anterior los alcances doctrinarios de Kelsen, son sustentados en su obra denominada "La garantía jurisdiccional de la Constitución" (1928), en ella desestima la capacidad de autocensura y moderación legislativa por parte del Parlamento -en lo relativo al resguardo de la jerarquía normativa de la Constitución- y ante ello postula las bondades de un órgano autónomo del Parlamento para que actúe como legislador negativo, con facultades de anulación de las leyes contrarias a la Constitución ${ }^{20}$.

El razonamiento que lleva a Kelsen a justificar la presencia de los TC es sencillo; las normas que forman la pirámide se fundamentan cada una en su inmediata superior, a la cual no pueden contradecir; la pirámide está presidida por la Constitución, que es la norma que regula la producción de las normas inferiores (ley, reglamento y acto administrativo o decisión jurisdiccional); la ley se ha de adecuar a la Constitución, el reglamento se ha de adecuar a su vez en la ley y el acto administrativo o la decisión jurisdiccional han de adecuarse a la ley o reglamento. Carece de sentido preguntarse si han de ser justos o injustos, lo único sagrado es que todas las sentencias, actos; reglamentos y leyes sean coherentes con su norma superior inmediata, desde la base de la pirámide hasta la cúspide.

Como en Austria, antes de 1920 no se cumplían los requerimientos de certeza del derecho y garantía de la Constitución, y como los tribunales supremos -de tipo norteamericano- no le ofrecían garantías de asegurar la certeza a causa del carácter solamente incidental y difuso de su control, de cara a la nueva Constitución de 1920, Kelsen propuso la creación de un TC, cuya función principal había de ser velar por la coherencia y constitucionalidad de todo el ordenamiento normativo de la Constitución, para lo cual tendría la facultad de

Civitas, Madrid, 2001, p.123.

${ }^{19} \mathrm{Cfr}$. QUIROGA LEÓN, Aníbal, La Interpretación Constitucional, Fondo Editorial del Perú, № 39, setiembre, 2005, p. 324.

20 Cfr. EGUIGUREN PRAELI, Francisco, Los Tribunales Constitucionales en la Región Andina: Una Visión comparativa, Revista de la Facultad de Derecho de la Pontificia Universidad Católica del Perú, № 53, diciembre 2000, pp. 7-64. 
anular las leyes contrarias a la Constitución. De esta forma se convierten en supremos garantes e intérpretes de la Constitución, función, que como es evidente, poco tiene que ver con la de un Tribunal supremo europeo continental ordinario.

Otro de los fundamentos que motiva la creación del TC, es la defensa del orden constitucional incluso de parte de los mismos jueces, esto ocurre, cuando los tribunales de justicia ordinarios no son capaces de garantizar el orden constitucional. Éste cuestionamiento del papel de los órganos judiciales ordinarios, fue un factor decisivo para la adopción de Tribunales Constitucionales, autónomos y ajenos al Poder Judicial ${ }^{21}$.

Desde luego esta propuesta de creación de un TC, no se extendió a la totalidad de los países con Constitución escrita, de hecho, como afirma Díaz Revorio ${ }^{22}$ frente a la "naturalidad" de que sea el Poder Judicial quien asuma la garantía de la supremacía constitucional, la creación de una Jurisdicción Constitucional (en concreto, de un Tribunal Constitucional) se ha llegado a considerar como "una anomalía histórica presente y con proyección de futuro" 23 o como un "cuerpo extraño que atenta contra el principio de separación de poderes" 24 .

En contraposición a los fundamentos que originan la creación del Tribunal Constitucional - desde la perspectiva kelseniana antes detallada- surge la postura de Carl Schmitt con su clásico libro "El protector de la Constitución", allí expone la necesidad de que el órgano tutelar de normas constitucionales fuera de carácter eminentemente político, es decir que recaiga en la figura del Presidente de Reich, para lo cual Schmitt recurrió a la tesis del poder neutro de Benjamín Constant. En su concepto, conferir dicha función a los tribunales ordinarios o alguno en especial, implica no sólo la "judicialización de la política" sino también una "politización de la justicia"25.

21 Cfr. CAPELLETI, Mauro, Conts Conntitutionelles, Citado por EGUIGUREN PRAELI, Francisco, Ob. Cit. pp. 7-64.

22 Cfr. DIAZ REVORIO, Francisco Javier. Ob. Cit. p. 83

23 PÉREZ ROYO, Javier, Curso de Derecho Constitucional, 5ta

Edición, Madrid, España, Marcial Pons, 1998 p. 675

${ }^{24}$ REQUEJO PAGES, Juan Luis, Tribunal constitucional, jurisdicción ordinaria y derechos fundamentales, Revista Española de Derecho Constitucional, № 50,1997, p. 251.

${ }^{25} \mathrm{Cfr}$. SCHIMITT, Carl, Ob. Cit. pp. 57-60.
Hans Kelsen dio a conocer sus observaciones y críticas bajo el título "¿Quién debe ser el protector de la Constitución? el cual estimaba que la postura de Schmitt era ideológica, porque el órgano para proteger las normas fundamentales debía ser un tribunal especializado que no tendría que considerarse como cualitativamente diferente de cualquier otro órgano jurisdiccional, así tendrá que actuar como legislador negativo, ya que no genera sino que destruye una reforma general" ${ }^{26}$. En definitiva, Kelsen no ve lógico otorgar la misión de proteger la Constitución a un poder existente ya que podría tener un predominio y sustraerse a su vez a todo control, y estima oportuno crear un poder especial específico, que sería un Tribunal Constitucional ${ }^{27}$.

Más allá del debate generado en torno a la existencia, naturaleza y funciones del Tribunal Constitucional, el tiempo y las circunstancias ha demostrado que ésta institución es de gran importancia pues defiende y garantiza la Jurisdicción Constitucional la cual toma como presupuestos, el principio de supremacía jerárquica de la Constitución sobre cualquier otra norma del sistema jurídico, así también implica el sometimiento del ejercicio de la fuerza estatal a la racionalidad del derecho, garantizando el pleno respeto de los principios, valores y normas establecidas en el texto fundamental ${ }^{28}$, y aún sin perder su carácter político-legislativo, desarrolla funciones judiciales e incluso se convierte en un auténtico tribunal supremo de facto. ${ }^{29}$

Lo antes dicho demuestra que las posturas que afirman que el TC no debería existir en un Estado Constitucional -adecuado al concepto- son equivocadas. Las funciones exigidas por la propia naturaleza del Estado como forma política, una vez que el poder constituyente ha manifestado su voluntad, son tres y nada más que tres: la legislativa, la ejecutiva y la judicial ${ }^{30}$ por tanto la presencia del TC no destruye la separación de poderes sino que por el contrario se

${ }^{26}$ KELSEN, Hans, ¿Quién debe ser el Defensor de la Constitución?, Tecnos, Madrid, 1995, pp. 27-39.

${ }^{27}$ Cfr. KELSEN, Hans, Ob. Cit. pp. 50-57.

28 Cfr. GARCíA TOMA, Víctor, Teoría del Estado y Derecho Constitucional, Ob. Cit. p. 517.

${ }^{29} \mathrm{Cfr}$. PEREIRA MENAUT, Antonio Carlos, Lecciones Elementales de teoría Constitucional, Colex, España, 1997, p. 283.

${ }^{30}$ Cfr. PÉREZ ROYO, Javier, Ob. Cit. p. 676. 
encarga de limitar y garantizar que sus funciones se adecuen a las normas contenidas en la Constitución, por ser la Constitución Lex Suprema, la cual da vida a todas estas instituciones.

\subsection{Naturaleza del TC}

A partir de la Segunda Guerra Mundial se produce un renacimiento de la Jurisdicción Constitucional y con ello del conjunto de funciones a cargo de los TC. Según Álvarez Cond $^{31}$, ello se debe básicamente, a las siguientes consideraciones:

a. El TC, surge como reacción ante la crisis del concepto clásico de la Constitución. Se acepta que la Constitución deje de ser una simple declaración de principios y se convierta en norma directamente aplicable.

b. El TC, es consecuencia del principio de la supremacía de la Constitución, por lo cual la doctrina ha dicho que sólo es posible en aquellos sistemas políticos dotados de Constitución rígida.

c. El TC, debe ser considerada como una manifestación del Estado de Derecho, en cuanto supone la consagración del principio de legalidad constitucional, la tutela de los derechos y libertades y la aceptación del principio de división de poderes, tanto en su aspecto horizontal como vertical.

Los TC son el instrumento de defensa de la Constitución por excelencia. Pero debe entenderse que la Constitución comprende el Preámbulo, las normas constitucionales y los principios y valores constitucionales, todo lo cual forma una unidad sistemática. Hay que tener en cuenta que la interpretación constitucional de los TC vincula a los ciudadanos y a los poderes públicos. Estos tribunales son órganos constitucionales. En efecto, tienen competencia constitucional; su existencia, funciones y estructura básica son establecidas por la Constitución. Por tanto, el juez constitucional se diferencia del juez ordinario.

${ }^{31}$ Cfr. ÁLVAREZ CONDE, Enrique, Curso de derecho constitución, Vol. II, Tecnos, Madrid, 2000, p. 281.

32 Cfr. SAGÜÉS, Néstor Pedro, Elementos de Derecho Constitucional, Tomo I, Editorial Astrea, Buenos Aires, p. 169.
En cuanto a su naturaleza, los TC se pueden concebir como órganos únicos, judiciales - desde un punto de vista estrictamente jurídico- pero también al respecto hay varias teorías. Algunos autores afirman su naturaleza jurisdiccional; otros sostienen su cariz legislativo; unos pocos, la naturaleza administrativa y finalmente parte de la doctrina hace hincapié en que son órganos de justicia política.

A continuación abordaremos cada una de estas concepciones.

\subsubsection{TC como órgano único}

Poco vale el principio de supremacía constitucional, sino se proyecta un aparato de control de esa supremacía. Esto es un Tribunal Constitucional, que opere como órgano de control, mediante el cual se pueda efectivizar la superioridad de la Constitución ${ }^{32}$.

Kelsen propone un régimen concentrado de revisión de constitucionalidad, es decir, centralizado en un Tribunal Constitucional, que opera como órgano extrapoder fuera de los tres poderes clásicos- estableciéndose que no hay control efectivo de constitucionalidad si el órgano de control no está habilitado para derogar a la norma inconstitucional y fallar con efectos generales (erga omnes). Esto importa un enorme poder políticoinstitucional que no puede confiarse al Poder Judicial clásico y al Parlamento sino a un cuerpo intermedio, dicho órgano debe estar compuesto con magistrados con participación del Poder Legislativo y por períodos limitados, a fin de guardar cierta correspondencia ideológica con los cambios políticos operados en la sociedad y proyectados al Parlamento 33 . "Por tanto, tal órgano sea o no un tribunal, es cuestión meramente formal, y carente de importancia: se trata de un "legislador negativo" y su función es la "legislación negativa" 34 .

Estos órganos especializados, no juzgan conforme al derecho, sino con arreglo a la Constitución, ésta es la justificación que se presenta para que no sean intérpretes del ordenamiento jurídico como tal, sino de la Constitución y de una Constitución formal jurídicopositiva, esta es su razón de ser, el asegurar que todas

\footnotetext{
${ }^{33}$ KELSEN, Hans, Ob. Cit. p. 178.

34 PEREIRA MENAUT, Antonio Carlos, En Defensa de la Constitución, Universidad de Piura. Colección Jurídica, 1997, p. 290.
} 
las normas sean conforme a ella, ya que ella es la norma "fundante" encontrándose en la pirámide normativa, norma de normas y regla para la creación de normas jurídicas esenciales del estado, determinación de los órganos y del procedimiento legislativo ${ }^{35}$.

La Constitución Federal de la República austriaca del $1^{\circ}$ de octubre de 1920 contemplaba la regulación del Tribunal, que se encontraba integrado por un presidente, un vicepresidente y un número indeterminado de miembros titulares y suplentes, elegidos por mitad por el Consejo Nacional y por el Consejo Federal, con posterioridad el número de componentes del Tribunal se fijará en doce miembros titulares y seis suplentes. Tras la segunda guerra mundial, varios sistemas europeos crean Tribunales Constitucionales, basados en el sistema austriaco o kelseniano y quizá con algunas influencias del sistema norteamericano ${ }^{36}$.

\subsubsection{TC como órgano legislativo (negativo)}

El sistema europeo originario de control de la constitucionalidad de la ley, encuentra su fundamento doctrinal en los postulados teóricos de Hans Kelsen, para quien el Tribunal Constitucional asume funciones legislativas, solamente de carácter negativo; "aplicando la Constitución a un hecho concreto de producción legislativa y llegando anular leyes anticonstitucionales lo cual no genera sino destruye una norma general, es decir, pone el actus contrarius correspondiente a la producción jurídica, o sea, que oficia de legislador negativo"37, y "es que el Tribunal Constitucional existe no para hacer algo, sino para evitar que se haga lo que no se debe hacer" 38 .

Para el eminente jurista austriaco, con la asunción de éstas funciones no se contradice con el principio de separación de poderes, lo cual se da en razón a dos motivos: Primero, porque dichas funciones se asumen con la finalidad de controlar la conformidad de la actuación del legislador a la Constitución, considerando Kelsen que este control se da plenamente conforme al

${ }^{35}$ Cfr. KELSEN, Hans, Ob. Cit. pp. 152-153.

${ }^{36}$ Cfr. FERNÁNDEZ SEGADO, Francisco, El Sistema Constitucional Español, Dykinson, Madrid, 1992, p.

1044.

37 KELSEN, Hans, ¿Quién debe ser el Defensor de la Constitución?, pp. 36-37 citado por DÍAZ REVORIO. F. Javier, El Control De Constitucionalidad De Las Omisiones Legislativas Relativas En El Derecho Comparado Europeo, 2008 [ubicado el 27.VI 2008]. principio de división de poderes, resultando necesario garantizar jurídicamente la supremacía de la Constitución, y en Segundo lugar, porque se parte de que la participación del Tribunal en dicha función legislativa es exclusivamente negativa ${ }^{39}$.

Fernández Segado afirma lo siguiente,

“(...) la anulación de la ley a que se refiere Kelsen presenta un valor muy distinto al de la mera "desaplicación", característica de la revisión judicial norteamericana. Y ello por cuanto la anulación de la ley presenta el mismo carácter de generalidad que su elaboración, no siendo, por así decirlo, más que la confección con un signo negativo, lo que es tanto como afirmar que tal anulación participa de los rasgos propios de la función legislativa. De ahí que Kelsen conciba al Tribunal Constitucional no tanto como un órgano jurisdiccional en sentido estricto, cuanto como un "legislador negativo" 1 .

En este sentido Kelsen aclara que, aunque el órgano a quien se confía la fiscalización de la constitucionalidad se organice en forma de Tribunal con el fin de asegurar la independencia de sus miembros, no ejerce en realidad una función jurisdiccional, en palabras del mismo Kelsen: "anular una ley significa poner una norma general, ya que tal anulación por sus efectos erga omnes tiene el mismo carácter de generalidad que la producción de la ley, siendo por así decirlo, una producción de signo negativo, y por tanto una función legislativa. Es un tribunal que tiene el poder de anular las leyes $y$, en consecuencia, órgano del poder legislativo" ${ }^{\prime 1}$.

\subsubsection{TC como órgano jurisdiccional}

La Constitución es la norma suprema, por lo que entraña ineludiblemente la necesidad de una garantía jurisdiccional, dicha garantía es un elemento encaminado a asegurar la regularidad de los actos

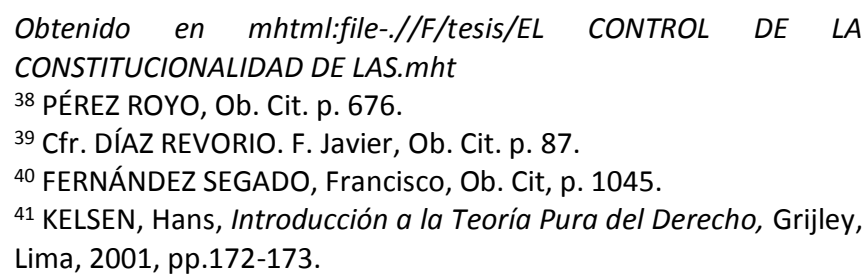


jurídicos de creación o de aplicación del derecho, entendiendo que la idea de regularidad, indica la necesaria relación de correspondencia que debe existir entre una norma de grado inferior y otra de grado superior del orden jurídico, esencialmente entre las medidas técnicas orientadas a garantizar la ya aludida regularidad se da en relación del acto inconstitucional la que de manera más eficaz representa la garantía de la Constitución ${ }^{42}$.

Por esto, el Tribunal Constitucional desde un primer momento, fue concebido por Kelsen como órganos de naturaleza legislativa y no judicial ${ }^{43}$, destinados a garantizar que las constituciones no resultasen falseadas por leyes inferiores a ella. Pero ocurre, que desde su mismo nacimiento, en 1920, Kelsen le añadió ya alguna función de carácter jurisdiccional, al resolver en calidad de tercero imparcial, en los conflictos entre la federación (austriaca) y los estados miembros. Debido a las circunstancias de los diversos países donde esta institución existe, han hecho que los Tribunales Constitucionales, aun sin perder su carácter políticolegislativo, desarrollen funciones judiciales e incluso se conviertan en los auténticos tribunales supremos de facto $^{44}$.

EI TC de acuerdo a Landa ${ }^{45}$ es eminentemente una instancia de fallo, la propia Constitución peruana de 1993, le atribuye competencia para conocer, en instancia única, los procesos de inconstitucionalidad y los conflictos de competencia; $y$, para conocer, en última y definitive instancia, las resoluciones judiciales denegatorias de los procesos constitucionales de habeas corpus, amparo, habeas data y cumplimiento.

De ahí que, el hecho de que la Constitución peruana no comprendiera al TC como un órgano del Poder Judicial, no le priva de su carácter de órgano jurisdiccional; por el contrario, el TC asume la función de impartir justicia constitucional, puesto que le ha sido atribuida no sólo la función constitucional de velar por el cumplimiento del principio jurídico de supremacía de la Constitución,

\footnotetext{
42 Ibídem, pp. 1044-1045.

${ }^{43}$ Cfr. GARCIA DE ENTERRIA, Eduardo, La Constitución como Norma y el Tribunal Constitucional, Ob. Cit. p. 132.

${ }^{44}$ Cfr. PEREIRA MENAUT, Antonio Carlos, Ob. Cit. p. 283

45 LANDA ARROYO, César, Autonomía procesal del Tribunal Constitucional, En: "La Ciencia del Derecho Procesal Constitucional,
}

sino también velar por la vigencia y eficacia de los derechos fundamentales:

En tanto órgano jurisdiccional, el TC asume un activo control de constitucionalidad, no sólo como legislador negativo, sino también como un auténtico promotor del respeto de los derechos fundamentales, precisando el contenido y límite de las disposiciones de la Constitución a través de la interpretación jurídica y de la teoría de la argumentación. Dicha constatación permite sostener que el modelo de la justicia constitucional kelseniano puro y simple ha sido superado, en la medida que en el texto Constitucional no sólo existen derechos fundamentales, sino también principios constitucionales y valores superiores, que el TC tiene como misión esencial tutelar y a veces antes desentrañar.

\subsubsection{TC como órgano político}

Sobre el tema Landa ${ }^{46}$ manifiesta que, cuando se refiere a la naturaleza política del Tribunal Constitucional, en definitiva, no se alude al sentido tradicional del término, como puede ser el de "hacer política"; sino el de "hacer derecho". Por eso, antes bien, se trata de una concepción que nace a partir de su reconocimiento -en última instancia- como vocero del poder constituyente, en la medida que es el intérprete supremo de la Constitución. Esta concepción, a su vez, se encuentra determinada tanto por sus decisiones, que pueden tener efectos políticos, como por la posibilidad de someter a control constitucional las denominadas cuestiones políticas.

Si bien la tensión entre política y derecho -es decir, entre la ley del Congreso y la sentencia del Tribunal Constitucional- es un conflicto universal y permanente, es posible afirmar que el rol jurídicopolítico del Tribunal Constitucional cobra mayor relevancia cuando acuden a esta instancia personas naturales o jurídicas con problemas económico sociales que no son resueltos por el mercado, que

Estudios en Homenaje a Héctor Fix Zamudio en sus cincuenta años, Tomo II. FERRER MAC-GREGOR, Eduardo. Coord. UNAM. México, 2008. pp. 239-242.

${ }^{46}$ Ibídem 
afectan el rol social del Estado, o cuando existe bajo consenso político entre la oposición con el gobierno al expedir una ley; generándose la influencia de los poderes privados y fácticos en la esfera de decisión judicial.

En tal sentido, se debe tener en cuenta que en países con una tradición desintegrada e inestable, como el Perú, donde la realidad política es conflictiva, el Tribunal Constitucional que resuelve en forma jurídica conflictos de contenido siempre político, no puede hacerse la ilusión de estar situado, ante la opinión pública, por encima de contiendas que él mismo ha de juzgar, sino que las modernas técnicas de la interpretación y argumentación constitucional pueden generar consensos conjugando la ratio y la emotio que toda Constitución representa ${ }^{47}$

\subsubsection{TC como órgano de control de la constitucionalidad}

Kelsen consciente no sólo de éste control político de la ley, sino también de la libre discrecionalidad de los jueces para dirigir sus fallos que inevitablemente ponían la validez del derecho en la conciencia de los hombres y no en el mandato de la ley, sugirió la creación de TC especializados para controlar la Ley Fundamental y a los jueces ${ }^{48}$.

El control de la constitucionalidad parte de una Constitución rígida, puesto que si ella es totalmente flexible puede ser reformada por leyes ordinarias, entonces no cabría protección de la Constitución ante la ley inconstitucional, por lo tanto toda ley sería constitucional ${ }^{49}$. Es así que "se debe apreciar a la Constitución como un conjunto de significado unitario y que debe tener siempre presente el sistema implantado por la norma suprema como un conjunto global, cuya preservación debe orientar sus decisiones" 50 . Por estos motivos "el control de constitucionalidad exige un cuerpo especializado, a

\footnotetext{
47 Ibídem

${ }^{48}$ Cfr. ASTETE VIRHUEZ, Jorge, El Poder Neutro: Teoría del Equilibrio de Poderes en el Perú, Lima, Instituto peruano de derecho constitucional, 2001, p. 93.

${ }^{49}$ Cfr. SAGÜÉS, Néstor Pedro, Ob. Cit. p. 174.

${ }^{50}$ FERNÁNDEZ SEGADO, Francisco, Ob. Cit. p. 1053.

${ }^{51}$ SAGÜÉS, Néstor Pedro, Ob. Cit. p. 173.
}

fin de garantizar una mayor capacitación entre sus miembros y una suerte de mentalidad constitucionalista al dictar sus sentencias" ${ }^{15}$.

El TC, tiene atribuida la función de controlar que la Constitución rija efectivamente como norma jurídica fundamental, entendiéndose que opera el principio de supremacía de la Constitución al disponer no sólo que la Constitución esté por encima de la ley, sino al atribuir que la Constitución está por encima de todas las normas del ordenamiento jurídico, poseyendo por tanto una mayor energía correctora en su encargo de control constitucional ${ }^{52}$. El Tribunal Constitucional conduce, a la cancelación definitiva de la ley ó disposición impugnada del ordenamiento jurídico, con una eficacia erga omnes, con efectos ex tunc (irretroactividad) $^{53}$.

Astete, al respecto afirma que, "Este control constitucional se hallaba en la interpretación de la ley, decidieron antes sustraerlo del legislativo para así otorgarlo a la nueva institución. Los parlamentos europeos dejaron entonces de ser un "jurie constitutionnaire" o Jurado Constitucional, los cuales dejaron de interpretar la ley" ${ }^{\prime \prime 4}$.

\subsection{Competencias adicionales del TC}

En el esquema kelseniano originario, no se incluían como funciones principales la protección de los derechos y libertades, ni la fiscalización de las operaciones electorales ni otros cometidos que después se han venido ejerciendo por los diferentes TC. Sin embargo la Constitución austriaca de 1920, reconoció a los ciudadanos un recurso de queja ante el Tribunal Constitucional para proteger sus derechos constitucionales violados, ya sea por la administración o por la aplicación de tratados internacionales, leyes o decretos anticonstitucionales.

Posteriormente esto fue lo que motivó que casi todas las Constituciones que han establecido una

52 Cfr. CASTILLO CóRdOVA, Luis, Comentarios al Código Procesal Constitucional, Ara editores, Lima, 2004, pp. 61-67.

${ }^{53}$ Cfr. FERNÁNDEZ SEGADO, Francisco, Ob. Cit. p. 1048.

54 ASTETE VIRHUEZ, Jorge, Ob. Cit. p. 114. 
Jurisdicción Constitucional concentrada han recogido más o menos ampliamente la protección de los derechos ${ }^{55}$.

\section{Conclusiones}

La idea de Jurisdicción Constitucional hace referencia al órgano $u$ orden jurisdiccional específicamente encargado de garantizar la supremacía constitucional. Así entendida la Jurisdicción Constitucional, puede o no existir, dado que, como se ha mencionado, puede haber garantía jurisdiccional de la Constitución sin que exista un órgano jurisdiccional especializado en esa labor. A diferencia de la Justicia constitucional, que surgió prácticamente en los orígenes del constitucionalismo para dar respuesta a la necesidad de garantizar el carácter de norma suprema de la Constitución, la jurisdicción especializada en lo constitucional, no surgió hasta el primer tercio del siglo XX, y no se extendió a la totalidad de los países con Constitución jurídica escrita. La jurisdicción especializada, nace en forma de un Tribunal Constitucional que, siguiendo los parámetros kelsenianos, queda fuera del Poder Judicial y de la clásica división tripartita de los poderes, actuando como un "legislador negativo", y monopolizando la función de rechazo de las leyes contrarias a la Constitución, que serán expulsadas del ordenamiento con efectos "erga omnes" cuando el Tribunal Constitucional declare su contradicción con la norma fundamental.
Jurisdicción Constitucional, es el término más acertado para referirnos a aquella "capacidad de los órganos del Estado para pronunciarse sobre temas constitucionales y que sus decisiones sean de carácter vinculante" pues su contenido es la magistratura constitucional, o sea los órganos a quienes les corresponden fijar en definitiva: el contenido y alcance de los derechos fundamentales, el alcance de los principios políticos establecidos en la Constitución y la implicación que tienen las entidades, órdenes y órganos de gobierno que la propia Constitución establece.

Puede entenderse ahora que la existencia de un TC se justifica al afianzar y arraigar el papel rector de la Constitución, como portadora de determinados valores materiales que son la base del ordenamiento jurídico, que le otorgan a éste su sentido $y$, en consecuencia, deben regir toda la interpretación y aplicación del orden jurídico.

EI TC, se convierte en un instrumento necesario de integración política y social, que coloca a la Constitución sobre los intereses ocasionales de los grupos políticos, se convierte en el órgano creado especialmente para generar consenso y sobre todo para hacer posible la efectiva garantía de la libertad y los derechos fundamentales como límites efectivos del ejercicio arbitrario del poder estatal.

55 Ibídem, 295. 